\title{
Çimentolu femoral komponent, tasarım ve uygulama
}

\author{
Cemented femoral component, design and application
}

\author{
Hakan Gürbüz, Murat Çakar
}

SBÜ Okmeydanı Eğitim ve Araştırma Hastanesi, Ortopedi ve Travmatoloji Kliniği, İstanbul

\begin{abstract}
Total kalça artroplastisi en sık uygulanan yetişkin rekonstrüktif kalça prosedürüdür. Tespit yöntemine göre başlıca çimentolu ve çimentosuz olarak ikiye ayrılabilir. Çimentolu kalça artroplastisinde kansellöz kemik ve protez arasında kilitlenmeyi sağlayan polimetilmetakrilat kullanılırken, çimentosuz total kalça artroplastisinde biyolojik tespit yapılır. Her iki sistemin de kendisine göre avantajları ve dezavantajları bulunmaktadır. Bu makale, çimentolu femoral protez türlerini ve farklarını irdelemeyi, uygulama esnasında dikkat etmemiz gereken ayrıntıları incelemeyi amaçlamaktadır.
\end{abstract}

Anahtar sözcükler: artroplasti; kalça artroplastisi; kemik çimentosu; çimentolu kalça artroplastisi
Total hip arthroplasty is the most commonly performed adult reconstructive hip procedure. According to the method of fixation, it can be divided into two as cemented and cementless. In cemented hip arthroplasty, polymethylmethacrylate is used to provide locking between cancellous bone and prosthesis. In cementless hip arthroplasty, this is provided by biological fixation. Both systems have advantages and disadvantages compared to one another. This article aims to examine the types and differences of cemented femoral prostheses and to review the details we need to pay attention during application.

Key words: arthroplasty; hip arthroplasty; bone cement; cemented hip arthroplasty
T otal kalça artroplastisi (TKA) en sık uygulanan yetişkin rekonstrüktif kalça prosedürüdür. Tüm dünyada her yıl bir milyondan fazla birincil TKA gerçekleştirilmektedir. ${ }^{[1]}$ Total kalça artroplastisi, tespit yöntemine göre başlıca çimentolu ve çimentosuz olarak ikiye ayrılabilir. Çimentolu TKA'da kansellöz kemik ve protez arasında kilitlenmeyi sağlayan polimetilmetakrilat kullanılırken, çimentosuz total kalça artroplastisinde biyolojik tespit yapılır. ${ }^{[2]}$

Çimentolu saplar iki geniş kategoriye ayrilır: "konik kayma" (veya "kuvvet kilitli") ve "kompozit kiriş" (veya "şekil kilitli"). ${ }^{[3]}$ Exeter sapı gibi konik kaymalı saplar, yakasız ve çok parlak bir yüzey kaplamasına sahiptir (Şekil 1). Stabilitesini çimento mantosu içinde hafif kaymaya neden olan protez-çimento ara yüzeyinde mikro hareket ile sağlar. ${ }^{[4-6]}$ Radyal gerilme kuvvetlerinin oluşması ile sonuçta kemik-çimento ve protez-çimento ara yüzeylerinde sıkışma gelişir. Charnley Stem'in daha sonraki versiyonları gibi, kompozit kiriş saplar, gövde-çimento ara yüzünde sert tespit sağlayan bir tasarımdır ve çimento mantosunun içindeki protez konumunu korur. ${ }^{[4-6]}$ Bu tasarımlar, çimentonun gövdenin yüzeyine nüfuz etmesini sağlayan, çimento ve gövde arasında bir katı bağ oluşturan mat veya dokulu bir yüzeye sahiptir (Şekil 2). En iyi tespiti oluşturmak için yüzey mat, kumlanmış, küçük metal boncuklar, trabeküler metal, gözenekli yüzey, ön kaplama veya girintilere sahip olabilir. ${ }^{[4-6]}$

Kompozit kirişli femoral komponent kullanılarak iyi sonuçlar elde edilebilir, ancak bu tip komponentlerde tolerans daha az olduğu için cerrahi uygulama çok iyi olmalıdır. ${ }^{[4,5]}$ Bir kompozit kiriş sapının kullanılması durumunda, yeterli kalınlığa sahip tam bir çimento mantonun yanı sıra hem gövde-çimento ara yüzeyinde hem de çimento-kemik ara yüzeyinde katı tespitin sağlanması esastır. ${ }^{[4-6]}$ Kompozit kiriş bileşenlerinin değişken sonuçlarının tersine, konik kaymalı sapların, mevcut tüm ulusal ortak kayıtlarda ve aynı zamanda bireysel yayınlarda birçok merkezde mükemmel sonuçlar verdikleri gösterilmiştir. Konik kaymalı saplar sadece aksiyel kuvvetleri değil torsiyonel kuvvetleri de ileten en güçlü ve en güvenilir

- İletişim adresi: Uzm. Dr. Murat Çakar, Kaptan Paşa Mahallesi, Darülaceze Cad. No: 25,Okmeydanı, Şişli, İstanbul Tel: 0505 - 2702922 e-posta: drmuratcakar@gmail.com

- Geliș tarihi: 24 Ocak 2019 Kabul tarihi: 24 Ocak 2019 


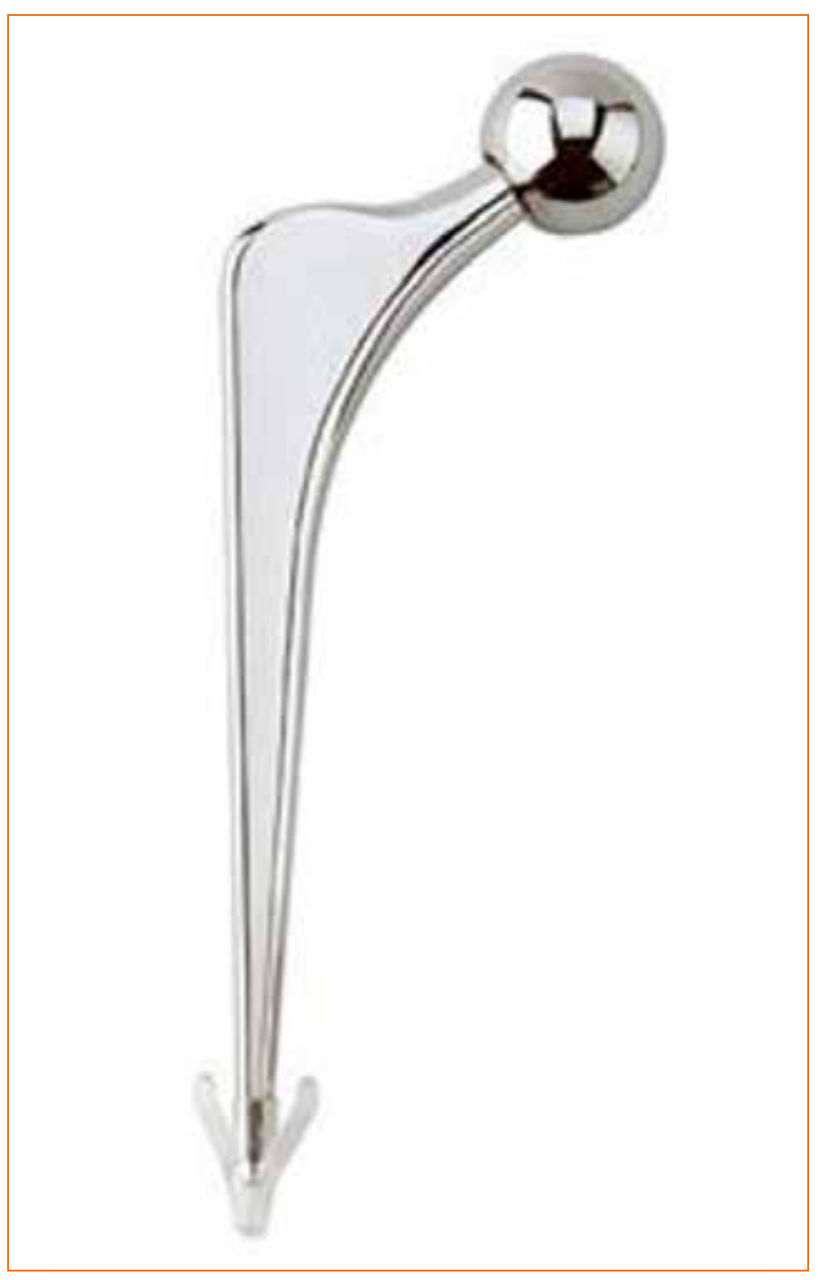

Şekil 1. Exeter çimentolu femoral sap.

yöntemlerden biridir. Konik kayma prensibi ile işlev görmek için, sap şekli konik ve cilalı bir yüzeye sahip olmalıdır; ayrıca, gövdenin, çimento mantonun içine girmesini önleyebilecek bir yaka gibi, sap üzerinde herhangi bir özellik olmamalıdır. ${ }^{[4-6]}$ Bu özelliklere sahip bir femoral sap, akrilik kemik çimentosunun visko-elastik davranışından yararlanabilir, çimento mantosunun iç yüzeyine zarar vermeden, gövde-çimento ara yüzeyinde harekete izin verir. Bu kaymanın üç önemli etkisi vardır:

- Femoral sap üzerindeki bir kuvvet sap-çimento ara yüzeyinde kayma yarattığından, biyolojik ara yüzeyde, yani kemik-çimento ara yüzeyinde, zararlı makaslama kuvvetlerine neden olmaz. Komposit kirişli saplarda ise, sap ve çimento üzerinden makaslama kuvvetleri doğrudan biyolojik ara yüze iletilir.

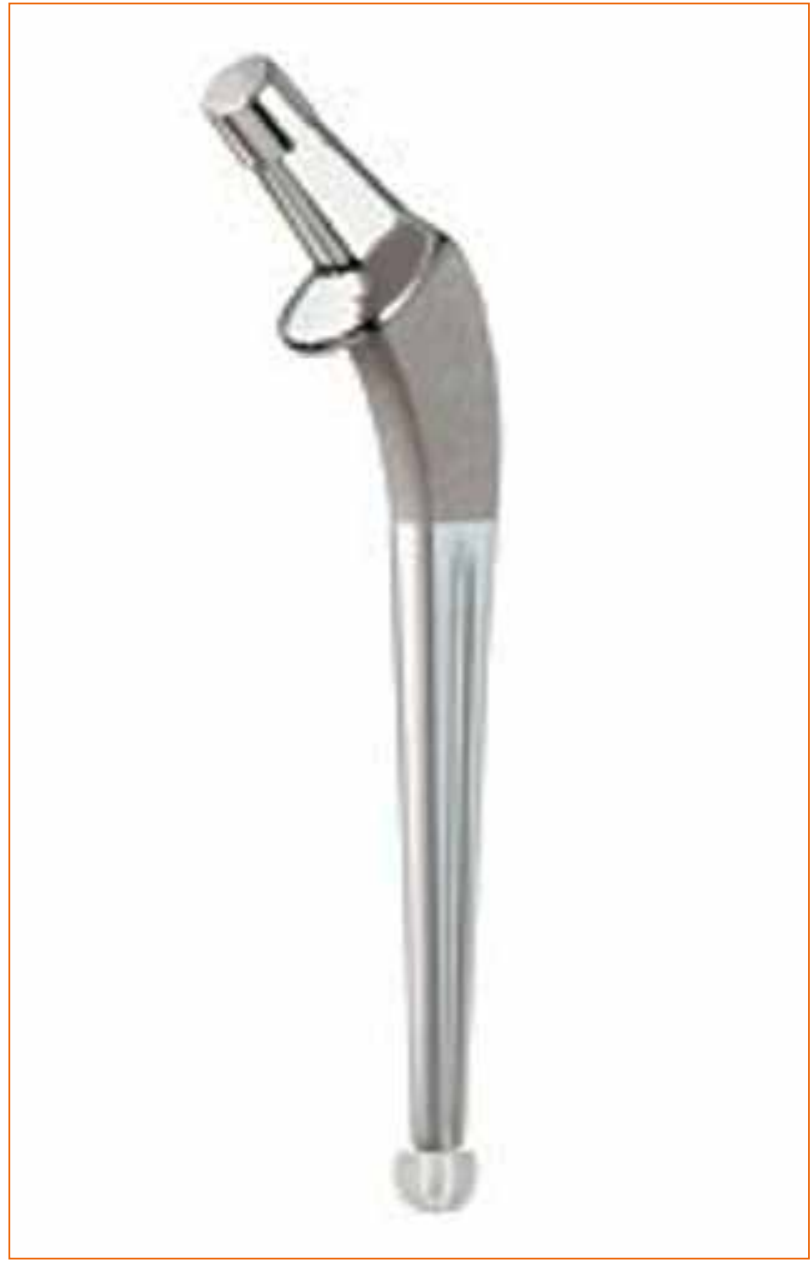

Şekil 2. Kompozit kiriş femoral sap.

- Sap kaydıkça çimento içinde çembersel gerilme kuvvetleri ile radyal kompresyon kuvvetleri oluşur. Radyal kompresyon kuvvetleri çimento-kemik ara yüzünü makaslama kuvvetinden korur. Dinlenme dönemleri sırasında çembersel gerilme kuvvetleri devam eder ve çimentonun gerilme stresini dağıtarak çimentonun gevşemesini sağlar. Bu mekanizma, çimentoyu yorulma kırılmasına karşı korur ve tüm yüklenme rejimi, sıkıştırma kuvvetleri tarafından sağlanır.

- Parlak sapın çimento içindeki kayması, sapın torsiyonel kararlılı̆̆ını arttırır.

\section{CERRAHI TEKNIK}

Çimentolu femur için kalçaya rutin insizyonlar ile girilebilir, özel bir cerrahi girişim gerektirmez. 
Parlak yüzeyli, konik, yakasız bir sap kullanıldığında boyun kesiminin seviyesi önemli değildir. Rezeksiyon çizgisi genellikle küçük trokanterin üst kenarı ile başın alt kısmının büyük trokanter ile karşılaştı̆̆ı nokta arasından geçmektedir. Ameliyat öncesi şablonlama ile, femur boynunda anormal varus veya valgus açılanmasının mevcut olup olmadığı belirlenmelidir. Koksa vara$\mathrm{da}$, boyun kesimi daha düşük bir pozisyonda yapılabilir ve gövdenin normalden daha fazla femoral kanal içine sokulması gerekecektir. Koksa valga olgularında, boyun kesimi normalden biraz daha uzundur, bu sayede femoral komponent kanal içerisinde iyi desteklenecektir. Femura yerleştireceğimiz aletlerin femoral kanalın orta hattında kalabilmesi için femur giriş yerinin femur eksenine $1 \mathrm{~cm}$ lateral olarak açılması önemlidir. Bu, bir kutu keski (box chiesel) kullanılarak gerçekleştirilebilir. Giriş yeri doğru yerden açıldığında, giriş oyucuları doğrudan popliteal fossa ortasına işaret eder. Daha sonra medüller kanal, konik oyucular kullanılarak genişletilir; oyucular ile genişletmede motor kullanılmamalıdır. Şablonlar ile belirlenen uygun offset'teki raspalar sırası ile kanala yerleştirilir ve aşırı kemiği aşamalı olarak kaldırmak için kullanılır. Femoral metafizdeki güçlü kansellöz kemiğin korunması önemlidir. En güçlü kansellöz kemik, femurun endosteal yüzeyine 3-4 mm mesafededir. Bu nedenle, bu kemiği kaldıracak motorlu oyucular ve büyük boy raspalar kullanılmamalıdır. Bacak uzunluğu ayarlanarak deneme yapılır. Hareket açıklığı, yumuşak doku gerginliği ve kalçanın stabilitesi eklemin tüm pozisyonlarında kontrol edilir. Deneme sistemleri çıkarıldıktan sonra femoral kanal için son hazırlık yapılırken, zamandan kazanmak için aynı anda çimento hazırlanmaya başlanabilir. Kanala uygun tıkaç femoral sap ucunun $1 \mathrm{~cm}$. altında kalacak şekilde sıkıca yerleştirilir. Medüller kanal agresif olarak basınçlı bir lavaj sistemi ile yıkanır. Kanal ve trabeküler kemik kan, yağ ve debristen arındırılır. Kanal içine ince bir emme kateteri yerleştirilip, salin solüsyonuna batırılmış şerit gazlı bezle doldurulur. Hipotansif epidural anestezi de kuru bir kansellöz yatak oluşturulmasında yardımcı olur. Genelde iki adet $40 \mathrm{~g}$ çimento düşük basınçlı bir vakum sistemi ile karıştırılır. Çimento hamuru, karıştırma işleminin başlamasından 1-2 dakika sonra çimento tabancasının haznesine dökülür. Süreyi belirleyen faktörlerden birisi de ameliyathane oda ISIsıdır. Daha önceden kanala yerleştirilen şerit gazlı bez çıkarılıp çimento retrograd basınçlı şekilde kanala verilir. Bu esnada, önceden konan emme kateterinin ucu tıkandığı an çekilip alınır. Çimento femoral sapın yerleşimine izin verecek kadar, hamur kıvamına gelene dek basınç korunur. Bu genellikle, ameliyathane oda sıcaklığı $20-21^{\circ} \mathrm{C}$ olduğunda, karıştırmanın başlangıcından yaklaşık beş dakika sonra gerçekleşir. Bu anın kontrolünü, cerrah elinde kalan artık çimento ile sağlayabilir.
Çimentonun viskozitesi uygun hale gelince, ortalayıcı içeren femoral komponent kanalın orta hat ekseni boyunca sokulur. Femurun anteversiyonu ve ön eğimi göz önüne alınarak, çimentoya giriş noktası, femur boynunun posterior kenarına yakın ve mümkün oldugunca lateralinde olmalıdır. Komponenti yerleştirirken rotasyon ve dizilimi kontrol edilmelidir. Femoral sap son pozisyonu aldıktan sonra, polimerizasyonu devam eden çimento mantosunun kırılmaması için hareket ettirmekten kaçınılmalıdır. Çimento polimerize olduktan sonra, baş denemesi tekrar yapılıp uzunluk ve yumuşak doku dengesi kontrol edilir.

Çimentolu femoral komponentin uzun süreli başarısı için;

- ameliyat öncesi şablon ile planlama yapılması,

- femoral kanala giriş yerinin iyi belirlenmesi,

- çimento kilitlenmesi için kalkar çevresinde en az 2-3 mm sağlam kansellöz kemik bırakılması,

- kemik yüzeyin iyi temizlenmesi için basınçlı bir lavaj sistemi kullanılması,

- femoral sapın uygun rotasyon ve dizilimde konulması,

- son nesil çimentolama tekniklerinin kullanılması,

- çimento implantasyon sendromunun cerrah ve anestezist tarafindan akılda tutulması ve

- çimentolu femoral kanalda sapın yerleştirilmesinden önce, sırasında ve sonrasında basıncın korunması gerekir.

Kalça protezi uygulamasında; uygun endikasyon konan hastalarda, cerrahi öncesi iyi planlama yapılarak ve çimentolama tekniğine dikkat edilerek, çimentolu femoral saplar ile etkili bir tedavi ve uzun sureli sağkalım elde edilmesi mümkündür.

\section{KAYNAKLAR}

1. Lee JM. The Current Concepts of Total Hip Arthroplasty. Hip Pelvis 2016;28(4):191. Crossref

2. Wyatt M. Survival outcomes of cemented compared to uncemented stems in primary total hip replacement. World J Orthop 2014;5(5):591. Crossref

3. Maggs J, Wilson $M$. The relative merits of cemented and uncemented prostheses in total hip arthroplasty. Indian J Orthop 2017;51(4):377. Crossref

4. Hoskins W, van Bavel D, Lorimer M, de Steiger RN. Polished Cemented Femoral Stems Have a Lower Rate of Revision Than Matt Finished Cemented Stems in Total Hip Arthroplasty: An Analysis of 96, 315 Cemented Femoral Stems. J Arthroplasty 2018;33(5):1472-6. Crossref

11. Hutt J, Hazlerigg A, Aneel A, Epie G, Dabis H, Twyman R, Cobb A. The effect of a collar and surface finish on cemented femoral stems: a prospective randomised trial of four stem designs. Int Orthop 2014;38(6):1131-7. Crossref

12. Çeliktaş M. Total kalça artroplastisi femoral komponent uygulama teknikleri. TOTBID Derg 2013;12(3):219-24. Crossref 